\title{
Violência contra a criança na óptica dos cuidadores de instituições de acolhimento
}

\author{
Violence against children in the view of host institutions caregivers \\ Violencia contra los niños en opinión de las instituciones de acogida \\ Ciderléia Castro de LIMA 1 \\ Melissa Joice de Abreu FELIZARDO2 \\ Lana Ermelinda da Silva dos SANTOS ${ }^{3}$ \\ Cristine Moreira Silva BENETTI ${ }^{4}$ \\ ${ }^{1}$ Enfermeira, Professora Mestre em Enfermagem, Universidade Federal de Alfenas (UNIFAL); \\ Universidade José do Rosário Vellano (UNIFENAS); 3710-000, Alfenas MG, Brasil \\ ${ }^{2}$ Enfermeira, Mestre em Enfermagem, Universidade Federal de Alfenas (UNIFAL);37130-000, Alfenas - MG, Brasil \\ ${ }^{3}$ Enfermeira, Pós Doutora em Enfermagem pela Universidade de São Paulo (USP/EERP); \\ Pró-Reitora de Graduação da Universidade Federal de Alfenas (UNIFAL); 37130-000, Alfenas - MG, Brasil \\ ${ }^{4}$ Acadêmica do Curso de Medicina, Universidade José do Rosário Vellano (UNIFENAS); 3710-000, Alfenas MG, Brasil
}

\begin{abstract}
Resumo
Introdução: A violência está presente em todas as culturas, sendo sempre seu maior alvo, os grupos de maior vulnerabilidade. Objetivo: Buscar a violência contra a criança sob a óptica dos cuidadores de instituições de acolhimento infantil. Material e método: Abordagem qualitativa do tema, extraída de dissertação de mestrado, realizado na cidade de Alfenas, MG, onde foram entrevistados 10 cuidadores de instituições de acolhimento. Resultados: Observamos a violência contra a criança em contextos diferentes. Pais ausentam-se de casa para trabalhar e as crianças ficam sozinhas ou sob a responsabilidade de outros. Pais negligenciam filhos devido às drogas. Observamos ainda, parentesco entre a vítima e o autor da agressão, que costuma ser uma pessoa mais velha. A cultura patriarcal, ainda muito forte, justifica os atos violentos. Por tal motivo, esse tipo de violência ainda é muito pouco notificada. Conclusão: Crianças vítimas apresentam dificuldade de relacionamento e autoaceitação. $\mathrm{O}$ assunto é complexo e envolve áreas que deveriam estar vinculadas, mas mostram-se desarticuladas. Os cuidadores, por sua vez, são revoltos com os pais das crianças, justificando a descrença no processo de reabilitação dos agressores. Entretanto, o envolvimento dos cuidadores no apoio às famílias, prevenindo violência contra a criança, é fundamental. Descritores: Violência; Institucionalização; Maus-Tratos Infantis.
\end{abstract}

\begin{abstract}
Introduction: Violence is present in all culture, always being their biggest target the most vulnerable groups. Objective: To seek violence against children from the perspective of caregivers of Child Care Institutions. Method: in the city of Alfenas, MG, were interviewed 10 caregivers. Results: we observed violence against children in different contexts. Parents absent themselves from home to work and the children are alone or under the responsibility of others. Parents neglect children due to drugs. We also observed kinship between the victim and the perpetrator of the assault, which is usually an older person. The patriarchal culture is still very strong which justify violent acts. Therefore, this type of violence still remains a little-reported. Conclusion: child victims have difficulty in relationships and self-acceptance. The subject is complex and involves areas that should be linked, but shows it's disjointed. Caregivers, in turn, are rough with the children's parents, justifying the disbelief in rehabilitation process of perpetrators. However, involvement of carers in supporting families, preventing violence against children, is critical.
\end{abstract}

Descriptors: Violence; Institutionalization; Child Abuse.

\section{Resumen}

Introducción: La violencia está presente en todas las culturas, siendo siempre su mayor objetivo de los grupos más vulnerables. Meta: buscan la violencia contra los niños desde la perspectiva de los cuidadores de los centros de atención infantil. Método: en la ciudad de Alfenas, MG, se entrevistó a 10 cuidadores. Resultados: se observó la violencia contra los niños en diferentes contextos. Los padres se ausentan de casa al trabajo y los niños están solos o bajo la responsabilidad de los demás. Los padres descuidan a los niños debido a las drogas. También observamos, el parentesco entre la víctima y el autor del asalto, que suele ser una persona mayor. La cultura patriarcal, sigue siendo muy fuerte, justificar actos violentos. Por lo tanto, este tipo de violencia es todavía muy poco contada. Conclusión: los niños víctimas tienen dificultades en las relaciones y la auto-aceptación. El tema es complejo e involucra áreas que deben estar vinculados, pero espectáculo es inconexo. Los médicos, por su parte, son ásperos con los padres de los niños, lo que justifica la falta de fe en el proceso de rehabilitación de los agresores. Sin embargo, la participación de los cuidadores en el apoyo a las familias, la prevención de la violencia contra los niños, es fundamental.

Descriptores: Violencia; Institucionalización; Maltrato a los Niños.

\section{INTRODUÇÃO}

Sabemos que o fenômeno da violência está instalado em todas as culturas, sem distinção de raça, etnia, idade, gênero e mesmo classe social. Suas vítimas se caracterizam por um grupo de maior vulnerabilidade. As crianças são vítimas de todo tipo de violência em todo tipo de contexto social, fato que desperta para o conhecimento e a compreensão desse fenômeno.
Contextualizar a violência torna-se um desafio a todos os pesquisadores envolvidos nessa temática, pois ela está entrelaçada a valores culturais, meios disciplinadores e com o poder conferido pela sociedade aos adultos. Uma vez estabelecida a dimensão do problema e sua repercussão, é possível viabilizar meios que favoreçam sua redução, minimizando seus efeitos. 
Para sustentar a importância de estudos que discutam e proponham estratégias de enfrentamentos da violência contra a criança, a epidemiologia é forte indicadora da complexidade do fenômeno. Dados mostram que em 2007, no Reino da Suazilândia (África), meninas na faixa etária de 13 a 17 anos foram forçadas à sua primeira relação sexual em contexto domiciliar. Mesmo sendo um ato cultural, práticas como essa, que são vistas de forma usual pela sociedade, podem ser compreendidas pela OMS como um ato de violação aos direitos da criança e do adolescente. Outros exemplos são a entrega das filhas de 10 anos ao casamento e a extirpação parcial ou total do clitóris em meninas de 5 a 10 anos de idade. Estudo complementar na Índia verificou em 13 estados que 53\% das crianças sofriam com o abuso sexual em suas diversas formas ${ }^{1,2}$.

Com relação à violência no continente americano, especificamente na América Latina e Caribe, destacamos dados referentes a 18 países. Neste contexto, $19 \%$ da população entrevistada relata conhecer ao menos uma criança vítima de abusos físicos por um membro da família. Dentre os países estudados estão El Salvador com 55\%; Costa Rica, com 53\%; Uruguai, com 44\%; Panamá e Colômbia, com 38\%; Venezuela, com 35\%; Equador com $33 \%$; Guatemala, com 31\%; No Brasil, Paraguai e Chile, a ocorrência foi de 30\%; Bolívia, de 29\%; Nicarágua, de 28\%; Argentina, de 27\%; Peru, de 23\%; México, de 21\%; Honduras e República Dominicana, de $19 \%{ }^{63}$. Nos Estados Unidos da América, em 2010, estimou-se que 12\% de crianças e adolescentes foram vítimas de agressões. Destas, $80 \%$ eram de caráter sexual ${ }^{1,2}$.

As diferentes formas de violência desencadeiam problemas diversos na saúde da criança. A violência como um grave desafio para a saúde coletiva deve ser abordada por profissionais de saúde em todos os níveis de atenção, primária, secundária ou terciária. É papel da equipe de saúde prestar assistência às vítimas e contribuir para a resolução desse problema, seja estabelecendo medidas de prevenção, medidas terapêuticas ou pesquisas sobre o tema ${ }^{4}$.

A violência pode desencadear hospitalização, sendo categorizada pelo CID-10 (Classificação Internacional de Doenças - 10) como Causas Externas. No Brasil, o Sistema de Informações Hospitalares do SUS - DATASUS, em 2009, registrou a taxa de hospitalização por causas externas. Entre as crianças de 5 a 9 anos, a taxa registrada em Minas Gerais foi de $15,1 \%$, São Paulo $13,3 \%$ e Rio Grande do Sul $11,7 \%$. Na faixa etária de 10 a 14 anos, as taxas registradas foram de $20,4 \%, 16,9 \%$ e $13,6 \%$, respectivamente.

A Bahia apresentou um percentual menor de hospitalizações por causas externas nessas respectivas idades. Na faixa etária de 5 a 9 anos a taxa foi de 8,9\%; de 10 a 14 anos, $11,7 \%$. Estes valores, entretanto, não são menos preocupantes ${ }^{5}$.

Entendemos que profissionais de saúde devem conhecer e compreender o fenômeno da violência contra a criança, desta forma é possível viabilizar meios para minimizar seus efeitos negativos sobre a vítima e a sociedade. Estudo ressalta a importância de estar o profissional de saúde bem capacitado frente aos casos que envolvem violência, por ser um fenômeno de ampla complexidade $^{6}$.

Instituições de acolhimento infantil, por sua vez, têm como objetivo desenvolver um trabalho que favoreça a formação de vínculo afetivo entre as crianças e o cuidador ${ }^{7}$. Trata-se de um desafio para estes profissionais, que devem saber lidar com a problemática social e deter habilidades para prestação de cuidados básicos, que supram as necessidades das crianças. Este contexto pode colocar também os profissionais em situação de risco. Os cuidadores podem apresentar dificuldades para a interpretação da realidade experienciada pelas vítimas, o que contribui para o desgaste emocional e dificulta sua atuação frente ao fenômeno da violência ${ }^{8}$.

Estudo mostra que a violência doméstica é o principal motivo que leva as crianças às instituições de acolhimento, fator este que caracteriza a estadia nestas instituições como transitória ${ }^{9}$.

Na práxis profissional, a compreensão da violência contra a criança auxilia na melhoria da assistência, com vistas a prevenir danos dela resultantes. Além disso, compreender o problema é essencial para fomentar discussões junto aos gestores do município para a resolução e redução desse tipo de violência, a qual confere um desafio à saúde pública. Tal problema necessita de maior número de estratégias e condutas em prol das vítimas. Estratégias estas que possam reduzir a dor física e emocional, medo, vergonha, sentimentos de culpa e isolamento que as crianças sofrem. Para isso, a articulação das redes de apoio torna-se imprescindível.

Mudanças culturais têm ocorrido, com vistas a valorizar a criança e diminuir o poder dos pais sobre ela Diante desta afirmativa, consideramos que alterações na percepção da violência como algo natural e um direito legitimamente exercido pelos pais, pode contribuir para sua redução ${ }^{10}$.

Esse estudo tem como objetivo geral conhecer e compreender a violência contra a criança sob a óptica dos cuidadores de instituições de acolhimento do município de Alfenas, MG.

\section{MATERIAL E MÉTODO}

Trata-se de um recorte de abordagem qualitativa, extraído da Dissertação de Mestrado intitulada $A$ compreensão da violência contra a criança sob a óptica dos cuidadores de instituições de acolhimento, Alfenas-MG. Tal Dissertação foi desenvolvida através de Programa de PósGraduação em Enfermagem da Universidade Federal de Alfenas (UNIFAL-MG).

O projeto de pesquisa foi submetido ao Comitê de Ética em Pesquisa da Universidade Federal de Alfenas, sob o Parecer favorável n.190/2011. O estudo foi desenvolvido na cidade de Alfenas, localizada no Sul de Minas Gerais. Segundo dados do IBGE, a cidade contava com uma população infanto-juvenil (faixa etária de 0 a 14 anos) de 18.752, o que correspondia a aproximadamente $23 \%$ da população $^{11}$.

Para análise dos dados qualitativos, utilizamos Bardim, método que busca indicadores para produção e recepção das mensagens. Isso é possível por meio de procedimentos sistemáticos, tais como: Pré-análise, momento em que as ideias foram organizadas após por leituras exaustivas; Desmembramento do texto em núcleos temáticos e codificação das entrevistas; Tratamento dos resultados através da interpretação e inferência das categorias emergidas $^{12}$.

\section{RESULTADOS E DISCUSSÃO}

$\mathrm{Na}$ temática da violência contra a criança, após entrevista com os cuidadores de instituições de acolhimento, foi possível identificar três eixos principais de discussão: Negligência e Abandono; Agressão Física; Violência Intrafamiliar. 
Durante as entrevistas, além de extrair as principais categorias de discussão, identificamos um grande desconforto dos cuidadores durante a abordagem da violência contra a criança. Este fato é compreendido e explicado uma vez que, falar sobre suas experiências com crianças violentadas significa reviver momentos desagradáveis.

Observamos que se trata de um assunto que envolve diversas áreas, tais como assistência social, saúde pública, valores culturais, aspectos psicoemocionais, estruturais e legais. Áreas estas que deveriam estar vinculadas entre si e aos órgãos de apoio, mas que se mostram desarticuladas no município.

\section{NEGLIGÊNCIA E ABANDONO}

Estudos evidenciam que as condições sociodemográficas vividas pelas famílias, tais como aspectos econômicos e uso abusivo de substâncias entorpecentes, contribuem para a grande incidência de maus-tratos contra a criança $^{13}$.

A negligência pode ser atribuída à necessidade de trabalhar para o sustento da família, o que leva os responsáveis a ausentarem-se. Muitos pais deixam os filhos por período temporário e/ou prolongado, sob os cuidados de outras pessoas, sem vínculos afetivos, ou até mesmo sozinhos. A ausência de um responsável favorece situações de risco, tais como violência e acidentes.

[...] às vezes a mulher sai para trabalhar porque o marido não tem aquela responsabilidade que deveria ter. A família não precisa ter dinheiro, mas eu acho que, o carinho $e$ o amor pelos filhos, fala mais alto ${ }^{(C 4 I A)}$. Desta forma, acreditamos que quando não se consegue conciliar o trabalho e a responsabilidade de pais, existe um ato de violência, pois os vínculos afetivos devem sobrepor a carência de dinheiro. A importância da afetividade no relacionamento com a criança, não sobrevalorizando a condição financeira é reafirmada por estudos ${ }^{14}$.

Por outro lado, os cuidados básicos negligenciados pelos pais devido ao uso de drogas deixam as crianças ainda mais susceptíveis, uma vez que estas já são a parte mais frágil do meio familiar e social.

A violência é um fato cotidiano na vida dos cuidadores de instituições de acolhimento, por estarem diretamente e diariamente envolvidos com crianças vítimas. Percebemos na fala dos cuidadores que a violência contra as crianças por eles assistidas tem relação direta às drogas. [...] aqui entram crianças que o pai mexe com drogas e que deixa elas, sozinhas (C3IA). [...] tem muitas crianças que os pais fazem tratamento e são usuários. Eu acredito que as drogas sejam o pivô de tudo, você não vê casos de pais que maltratam seus filhos estando sóbrios, você vê o álcool, a droga, a maconha, a cocaína ${ }^{(C 2 I B)}$.

A dependência de drogas, principalmente feminina, é um dos fatores que favorece a expressão da violência. Esta dependência leva à agressividade e à negligência de cuidados básicos aos filhos ${ }^{15}$

Negligência é entendida como omissão de proteção integral, o que interfere no desenvolvimento e crescimento da criança. Sua principal conseqüência é o abandono, a forma mais severa da negligência ${ }^{16,17,18}$

A falta de estrutura familiar e o envolvimento com drogas resultam em negligência com a criança. Portanto, consideramos necessário discutir sobre a família nesse contexto, levando em conta os aspectos sociodemográficos e econômicos. A fragilidade familiar e sua desestruturação comprometem os cuidados para com as crianças ${ }^{19}$

\section{AGRESSÃO FÍSICA: QUESTÃO DE PODER}

$\mathrm{O}$ uso de força física, para subjugar as crianças é causa de elevados números de notificações. Contudo, ainda podemos afirmar que são dados pouco fidedignos à realidade. Devido às agressões ocorrerem com maior frequência no ambiente doméstico, membros da família naturalizam os atos e até mesmo justificam-nos.

Crianças chegam às instituições de acolhimento devido à violência ou a situações de risco social a que são expostas. São crianças que foram surradas e abusadas sexualmente. Estas situações tendem a deixar marcas nas crianças, que acabam por sensibilizar o cuidador. [...] são maus - tratos, são pais usuários de drogas, bebidas alcóolicas, aí chegam maltratam os filhos com pontapés,

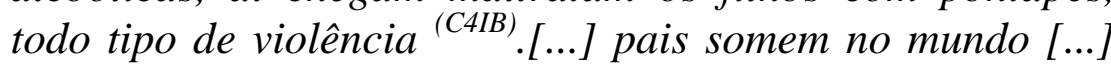
outros que apanham [...] eu achei que na minha cidade tinha violência, mas aqui, tem muito mais ${ }^{(C l I B)}$.

Abuso físico é caracterizado pelo uso da força física, também pode ser caracterizado como a intenção de provocar danos $^{20}$. Quanto maior for a exposição à violência parental, maior será a chance dessa criança ser autora de abusos físicos, caracterizando uma perpetuação do fenômeno.

O papel dos genitores e/ou responsáveis legais é de ser provedores, educadores e protetores. Contudo, os cuidadores da instituições infantis evidenciam que os pais faltam em suas responsabilidades, no papel de proteção integral à criança. [...] eu acho assim, espancar, bater. Tem mãe que não sabe bater, espanca; larga na rua. Pra mim isso é violência. [...] aqui tem muitos casos de violência, chego a chorar, chegam machucadas aqui ${ }^{\left({ }^{(C 3 I B)} \text {. }\right.}$

[...] tipo assim! Os pais espancam as crianças [...] sei lá. Qualquer pessoa, um tio, avó, ter coragem de bater, judiar, nossa eu fico revoltada ${ }^{(\text {(IIA) }}$. A relação de parentesco entre a vítima e o autor da agressão evidenciada pelos cuidadores é corroborada por estudos. Ambos afirmam ser o agressor, na maioria das vezes, pessoa mais velha, o que é comum no ambiente doméstico ${ }^{21}$. Culturalmente, isso pode ser justificado, uma vez que o mais velho exerce poder sobre os mais novos, subjugando as crianças. Este fator é, muitas vezes, banalizado pela sociedade.

Apresentamos a cultura patriarcal como favorecedora das práticas de violência, na imposição e no uso da força, em que o responsável pela criança sente-se dono da situação e com poder de autoridade para agir com violência ${ }^{22}$.

As relações de poder existentes na sociedade são vivenciadas pelo individuo e reproduzidas no ambiente familiar. Desta forma, o adulto leva a criança à submissão de sua autoridade. $\mathrm{O}$ sujeito acredita-se no direito de fazer uso de cinta, quando assim julgar necessário, como um método de correção. Esta situação é exacerbada quando associada às condições precárias $^{23}$.

Outro método disciplinador muito usado é o castigo, contudo, sendo ele severo ou não, quando usado de forma repetitiva, constitui uma prática de violência. Justificamos a violência uma vez que há imposição do adulto sobre a criança.

\section{VIOLÊNCIA INTRAFAMILIAR}

Nesta categoria, verificamos como os cuidadores fazem menção à falta de afeto e outras experiências traumatizantes vividas pelas crianças no ambiente familiar. Os profissionais relatam tratar-se de crianças tristes, por serem vítimas de violência extremada. [...] pais que já 
abusaram de crianças [...], imagina uma criança que foi abusada pelo próprio pai, como que é a cabeça dela?

Cuidadores observam ainda que as crianças trazem consigo lesões traumáticas, resquícios de experiências familiares, deixadas por pessoas com relação biológica e afetiva. Tais lesões tendem a apresentar marcas específicas do objeto usado para a agressão, tais como cintos, fivelas, dedos, dentes, cordas. Estas marcas podem diferir, no entanto, sendo marcos sugestivos de abuso e agressões freqüentes ${ }^{21}$. [...] às vezes o próprio pai violenta a criança em casa, né. Eu acho um absurdo né, um pai ter coragem de violentar uma criança ${ }^{\text {(CIIA) }}$

As crianças acolhidas nas instituições são amedrontadas, introspectivas e com dificuldades de relacionamento com outras crianças e até mesmo com os próprios cuidadores. Para eles, as crianças sofrem tantos tipos de violência em casa que passam a julgar todas as pessoas que delas se aproximam, acreditando terem todas o objetivo comum de causar-lhes mal. Estas crianças são apáticas, desmotivadas e, por vezes, revoltadas, o que dificulta estabelecer laços de confiança. Uma vez estabelecidos estes laços, as crianças fazem revelações de brutalidade. Infelizmente, em um terceiro momento, por medo e dependência familiar, acabam silenciando-se.

[...] elas vão adquirindo confiança, aí elas contam até detalhes do que viveram em casa [...], pai e mãe chegavam e faziam tudo junto com as crianças. Chegam aqui e querem fazer a mesma coisa, porque viam os pais fazendo, então pode fazer também ${ }^{(C 2 I A)}$. Acreditamos que a violência sexual praticada contra a criança em ambiente doméstico seja pouco notificada. Baixos índices de notificação decorrem do tabu que o sexo ainda representa à família. A UNICEF ${ }^{24}$ afirma que o meio familiar é cenário de atentado violento ao pudor em crianças de até 10 anos de idade. Neste contexto, os agressores são, em sua maioria, membros da família e pessoas próximas à criança. Fato este, convergente com o relatado acima pelos cuidadores.

Desta forma, a família, que deveria constituir um meio seguro para a criança, pode representar um meio gerador de conflitos, em que se vivenciam experiências traumáticas. Tais experiências tendem a ser reproduzidas nas instituições de acolhimento para onde estas crianças são encaminhadas.

O relacionamento entre os pais é outro importante fator na violência contra a criança. As crianças que presenciam a violência entre os pais, podem apresentar rendimento escolar reduzido, distúrbios de conduta, tendência à agressividade e baixa autoestima. Tais sintomas podem evoluir com doenças somáticas, resultando em um adulto violento, que reproduz atos violentos em seu ambiente familiar e/ou social ${ }^{25,26}$. O resultado pode ser, ainda, uma grande dificuldade de autoaceitação ${ }^{27}$. [...] o pai esfaqueou a mãe, está aí hoje, viveu isso dentro de casa [...] São crianças que chegam aqui inseguras, crianças que, são problemáticas, estragadas mesmo, bastante estragadas (C2IA). [...] pai rouba a própria mãe (esposa), deixa as crianças aqui e rouba a própria mãe (esposa) para sustentar $o$ vício (C4IA)

As condições físicas e emocionais em que as crianças são admitidas acabam por gerar nos cuidadores sentimentos de revolta à figura dos pais. Este fator causa desconfiança, por parte dos cuidadores, no momento das visitas e justifica a descrença no processo de reabilitação dos agressores. Estudo mostra, em contrapartida, que maus-tratos à criança são sintomas de disfunção familiar. Esta, por sua vez, não pode ser considerada uma situação definitiva ${ }^{28}$. Faz-se necessário, portanto, o envolvimento dos cuidadores no apoio às famílias, visando a prevenção da violência contra a criança.

Sabemos que, no acompanhamento social, devem ser desenvolvidas ações efetivas com vistas à reestruturação familiar. Dentre estas ações podemos destacar atendimento social aliado às visitas domiciliares, promoção de grupos de apoio e inserção da criança em programas de auxílio familiar $^{24}$.

\section{CONCLUSÃO}

Os traumas sofridos pela criança no meio intrafamiliar podem refletir no desempenho escolar e na vida adulta, como dificuldade de relacionamento, comportamento agressivo e introspecção.

Saber identificar o problema e discuti-lo com pauta nos direitos infantis poderá contribuir, em parte, para a redução das práticas de violência contra a criança.

Não há tempo pré-determinado para diminuir a violência contra a criança e tornar as políticas existentes mais efetivas. De qualquer forma, tais políticas devem ser revisadas com mais rigor e devem ser discutidos meios de monitoramento das famílias quanto aos riscos sociais que, direta ou indiretamente, favorecem a violência.

Por saber que as crianças ainda constituem o público de maior vulnerabilidade, consideramos importante colocar em pauta estratégias que envolvam todos os setores ligados à proteção a criança, no intuito de amenizar o impacto da violência na saúde infantil.

Suscitamos também ampliação da educação continuada dos cuidadores em instituições de acolhimento. Estes, frente a atos de violência, vivenciados na prestação de cuidados às crianças vitimizadas, denotam revolta com os pais, com o Poder Público e até mesmo com a sociedade. Isso, de forma inconsciente, pode ser transferido às crianças e influenciar no processo de desenvolvimento infantil e de adaptação social.

\section{REFERÊNCIAS}

1. NGO Advisory Council. Five years on: A global update on violence against children. October 2011. Disponível em: www.slideshare.net/ThomasMueller/five-years-ona-global-update-on-violence-againstchildren-13493486.

2. Organização Mundial de Saúde (OMS). Mulheres e saúde: evidências de hoje, agenda de amanhã, 2009. 93p. Disponível em: http://www.who.int/ eportuguese/ publications/Mulheres_Saude.pdf. Acesso em: 10 de jan. de 2013.

3. English C, Godoy J. Child Abuse Underreported in Latin America. World. 2010; June 4. Disponível em: http://www.gallup.com/poll/139376/child-abuse underreported- latin-america. aspx. Acesso em: 29 de nov. de 2012.

4. Barbosa PZ, Pegoraro RF. Violência doméstica e psicologia hospitalar: possibilidades de atuação diante da mãe que agride. Saude soc. 2008; 17(3):77-89.

5. Brasil Ministério da Saúde. DATASUS- Sistema de Informações Hospitalares do SUS (SIH/SUS) DATASUS. Disponível: http://tabnet.datasus.gov.br /cgi/tabcgi.exe?sih/cnv/fiuf.def. Acesso em: 28 de ago. de 2011.

6. Antonio EMR, Fontes TMP. Bioética e aspectos epidemiológicos de vítimas de violência sexual em hospital-maternidade. Rev Bioét. 2012; 20(2): 280-7.

7. Santos AMCO, Gonçalves CR, Sberge MA, Chalhub A. Vínculos afetivos entre crianças e cuidadores em uma 
instituição de abrigamento. (Inter)Subjetividades.2009; 1(1). Disponível em: http://revistas.unijorge.edu.br/ intersubjetividades/pdf/2009_Artigo6.pdf . Acesso em: 7 de out. de 2012.

8. Penna LHG, Carinhanha JI, Leite LC. A prática educativa de profissionais cuidadores em abrigos: Enfrentando a violência vivida por mulheres adolescentes. Rev Latino-Am Enfermagem. 2009; 17(6):981-7.

9. Cuneo MR. Abrigamento prolongado: Os filhos do esquecimento, a institucionalização prolongada de crianças e as marcas que ficam. Censo da população infanto-juvenil abrigada no estado do Rio de Janeiro. 2009; cap. 7, p.415-32.

10. Mascarenhas MDM, Malta DC, Silva MMA, Lima CM, Carvalho MGO, Oliveira VLA. Violência contra a criança: revelando o perfil dos atendimentos em serviços de emergência, Brasil, 2006 e 2007. Cad Saúde Pública. 2010; 26(2):347-57.

11. Instituto Brasileiro de Geografia e Estatítica (IBGE). Sinopse do censo demográfico 2010: distribuição da população por sexo, segundo os grupos de idade, Alfenas (MG), 2010. Disponível em: http://www.censo2010.ibge.gov.br/ sinopse/ index.php? dados=26\&uf=31. Acesso em: 14 de jul. de 2011.

12. Bardin L. Análise de Conteúdo. Lisboa: Edições 70; 2004.

13. Smith TK, Duggan A, Bair-Merritt MH. Systematic Review of Fathers' Involvement in Programmes for the Primary Prevention of Child Maltreatment. Child Abuse Review. 2012; 21(4):237-54.

14. Miles G, Stephenson P. Diretrizes para crianças em risco: crianças em instituições de acolhimento e alternativas. v. 5. Fiona Anderson: Freelance; 2001.

15. Bittar DB, Nakano AMS. Violência intrafamiliar: análise da história de vida de mães agressoras e toxicodependentes no contexto da família de origem. Texto contexto - Enferm. 2011;20(1):17-24.

16. Fernandes RT, Lamy ZC, Morsch D, Lamy Filho F, Coelho LF. Tecendo as teias do abandono: Além das Percepções das mães de bebês prematuros. Ciênc Saúde Coletiva. 2011; 16(10):4033- 42.

17. Apostólico MR, Nóbrega CR, Guedes RN, Fonseca RMGS, Egry EY. Características da violência contra a criança em uma capital brasileira. Rev Latino-Am Enfermagem. 2012; 20(2):266-73.

18. Minayo MCS. Violência e saúde. Rio de Janeiro: Fiocruz; 2006.

19. Santana AFS, Sampaio SMR. A heterogeneidade psicossociológica do fenômeno das crianças nas ruas. Poiésis. 2011; 4(8): 503-23.

20. Zanoti-Jeronymo DV, Zaleski M, Pinsky I, Caetano R, Figlie NB, Laranjeira R. Prevalência de abuso físico na infância e exposição à violência parental em uma amostra brasileira. Cad. Saúde Pública. 2009; 25(11):2467-79.

21. Assis SG, Deslandes SF. Abuso físico em diferentes contextos de socialização infanto-juvenil. In: Lima CA. Violência faz mal à saúde. Brasília, DF: Ministério da Saúde, 2006: 47-58. Disponível em:http://dtr2001.saude.gov.br/ editora/produtos/ livros/pdf/04_1059_M.pdf. Acesso em: 15 de jan. de 2013.

22. Silva CM, Maciel JA. Violência sexual intrafamiliar contra a criança e o adolescente na cidade de Gurupi/TO nos anos de 2007 e 2008 e o Código Penal Brasileiro após o advento da lei 12.015 de 2009. Revista Cereus. 2010 jun./ dez.; (3).

23. Almeida DSO, Martins RC. Criança: um histórico de violências. Educação em Revista. 2009; 10(2): 57-72.

24. Fundo das Nações Unidas para a Infância - UNICEF. Pequenas Vítimas, 2006.

25. Moura ATMS, Reichenheim ME. Estamos realmente detectando violência familiar contra a criança em serviços de saúde? A experiência de um serviço público do Rio de Janeiro, Brasil. Cad Saúde Pública. 2005; 21(4):1124 -33.

26. Berlin LJ, Appleyard K, Dodge KA. Intergenerational Continuity in Child Maltreatment: Mediating Mechanisms and Implications for Prevention. Child Dev. 2011; 82(1):162-76.

27. Delfino V, Biasoli-Alves ZMM, Sagim MB, Venturini FP. A identificação da violência doméstica e da negligência por pais de camada média e popular. Texto contexto - Enferm. 2005; 14(spe):38-46.

28. Pascolat G. Violência no lar contra a criança. Educar em Revista. 1999; (15). Disponível em: http://revistas.ufpr.br/educar/article/view/2056/1708. Acesso em: 03 de set. de 2012.

\section{CONFLITO DE INTERESSES}

Os autores declaram não haver conflitos de interesse.

\section{AUTOR PARA CORRESPONDÊNCIA}

Cristine Moreira Silva Benetti

cristine_benetti@hotmail.com

Submetido em 14/09/2016 Aceito em 13/10/2016 